\title{
Study on Low Temperature Performance of Li Ion Battery
}

\author{
Kejie Wang \\ College of Automotive Engineering, Shanghai University of Engineering Science, Shanghai, China \\ Email: 1174815041@qq.com
}

How to cite this paper: Wang, K.J. (2017) Study on Low Temperature Performance of Li Ion Battery. Open Access Library Journal, 4: e4036.

https://doi.org/10.4236/oalib.1104036

Received: October 17, 2017

Accepted: November 20, 2017

Published: November 23, 2017

Copyright $\odot 2017$ by author and Open Access Library Inc.

This work is licensed under the Creative Commons Attribution International License (CC BY 4.0).

http://creativecommons.org/licenses/by/4.0/

(c) (7) Open Access

\begin{abstract}
At low temperatures, especially when the temperature drops to -20 degrees, or even lower, the energy and power of lithium ion batteries are obviously decreased by [1] [2] [3] [4] [5]. In order to further grasp the lithium ion power battery charging characteristics at low temperatures and low temperature discharge performance test bench experiment simulates the low temperature environment, so as to ascertain the low charge discharge characteristics, provide the basis and guidance for the application of low temperature battery. In this paper, the cathode is three yuan for the anode material, graphite type 18,650 power lithium ion battery business as a research object of low temperature test, through the research on the low temperature performance of single battery, not only can provide the basis for the design of thermal management system of electric vehicle, but also provide theoretical and experimental basis for the AC excitation of heating.
\end{abstract}

\section{Subject Areas}

Electric Engineering

\section{Keywords}

Low Temperature, Charge, Discharge, Experimental Study

\section{Introduction}

In recent years, electric vehicles are developing rapidly, because of the unique advantages of electric vehicles. Various countries have carried out in-depth research on all aspects of electric vehicles, and achieved fruitful results. As the key component of electric vehicle, power battery has also developed rapidly in technology. The performance and cost of electric vehicles are significantly affected by the performance and life of power batteries. Lead-acid batteries, nickel cadmium batte- 
ries, nickel hydrogen batteries, lithium ion battery and super capacitor is more common on the electric vehicle power battery, lithium ion batteries for the advantages of long service life, low self-discharge rate, high power density, high energy density and no pollution, gradually replace lead-acid batteries, nickel metal hydride batteries and nickel cadmium batteries [6]. A power battery used for electric vehicles. Although lithium ion batteries have obvious advantages, the low temperature performance of lithium ion batteries is still a problem that cannot be ignored, and has attracted widespread attention. In low temperature environment, the charge discharge performance of lithium ion battery decreased significantly, lithium ion battery manufacturing enterprises and scientific research personnel have low charge discharge performance of lithium ion battery launched a lot of research work. The results show that the low temperature performance of lithium ion battery is due to the diffusion of lithium ion in the electrode, the surface charge transfer resistance and SEI film caused by factors such as [7]-[10], but did not determine the main factors influencing the performance of low temperature. The energy density decreased from $100 \mathrm{Wh} / \mathrm{kg}$ at 25 to $5 \mathrm{Wh} / \mathrm{kg}$ at -40 . The power density can be reduced from $800 \mathrm{Wh} / \mathrm{kg}$ at 25 to $10 \mathrm{Wh} / \mathrm{kg}$ at -40 .The experimental research results show that the battery power at low temperature decreased energy attenuation is the main cause of the increase of the interface impedance of electrolyte and electrode material particles, and not due to the ionic conductivity of decreased electrolyte caused by [1] [3] [5]. Obviously, in low temperature environment, the charge performance and discharge performance of Li ion battery are obviously different, so it is necessary to study [11] [12] with single low temperature discharge and low temperature charging. In the low temperature lower than 10 DEG C, although the discharge of lithium ion battery can decrease in energy and power, but the low temperature environment cannot charge, because of low temperature charge may cause precipitation and accumulation of lithium metal and lithium dendrite [13], lead to security risks. However, recent studies have shown that even if there is a lithium metal precipitation, it will soon react with carbon negative carbon to produce carbon compounds, thereby inhibiting the formation of lithium dendrites. It is therefore pointed out that charging with small enough current at low temperatures is also permissible. In this paper, the charge and discharge experiments of lithium ion batteries with 18,650 and three materials were carried out. The temperature gradient was set at $10^{\circ} \mathrm{C}, 0^{\circ} \mathrm{C},-10^{\circ} \mathrm{C},-15^{\circ} \mathrm{C},-20^{\circ} \mathrm{C},-25^{\circ} \mathrm{C}$, $-30^{\circ} \mathrm{C}$, respectively. The experimental results show that the discharge voltage of the low temperature drops greatly, and the discharge performance of the battery is seriously deteriorated, which is lower than some temperature environment and even cannot discharge, which seriously affects the use of the battery. The charging experiments at $25^{\circ} \mathrm{C},-15^{\circ} \mathrm{C}$ and $-25^{\circ} \mathrm{C}$ temperatures show that the low temperature charging not only has small charging power and long charging time, but also causes fatal damage to the battery, which seriously affects its service life. 


\section{Lithium Ion Power Battery Test Platform}

The structure of test platform for lithium ion power battery is shown in Figure 1. The charging and discharging equipment of $\mathrm{Li}$ ion power battery is CT-4008-5V60A-NFA produced by Shenzhen new will Electronics Co., ltd. CT-4008-5V60A-NFA is a battery charge and discharge device developed for battery monomer testing. The maximum voltage is $5 \mathrm{~V}$, and the test accuracy is up to $0.1 \mathrm{Mv}$. The high and low temperature alternating test box produced by Shanghai Su Ying Test Instrument Co., Ltd., model is GDJ-250. The range of temperature rise is $-60-150$, and the temperature control accuracy is +0.1 centigrade. The Figure 1 power test platform function of the temperature box is to simulate the different environmental temperature. During the test, the power battery will be placed in the temperature box. The temperature measurement device uses Agilent KFYS1GHT 34972A to display temperature measurement in real time. In this paper, 18,650 type power lithium ion commercial battery with positive electrode material of three yuan and negative graphite as the research object was tested at low temperature.

\section{Experimental Scheme of Battery at Low Temperature}

The size of the 18,650 type lithium ion battery is small, and it can be approximately considered that the battery has uniform heat generation and small internal and external temperature difference. Therefore, the whole battery temperature can be approximately estimated by measuring the surface temperature of the battery. As shown in Figure 2, Figure 2(A) high thermal conductivity (6 $\mathrm{W} / \mathrm{mK}$ ), ultra-low hardness (50Shore00), high electrical insulation (flame retardant grade $\mathrm{V}-0$, high voltage $13 \mathrm{Kv} / \mathrm{mm}$, volume $>1012 \mathrm{Ohm}-\mathrm{cm}$, low impedance) oil, high reliability, wide range of working temperature $(-45$ DEG -+200

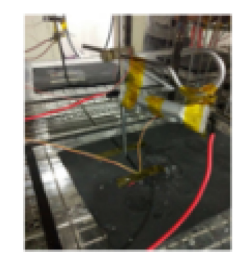

Built-in Heater Battery

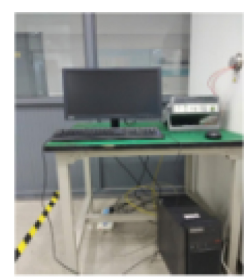

Agilent Thermometer

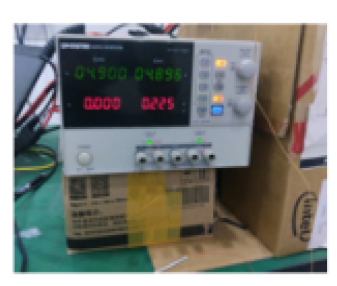

DC Power

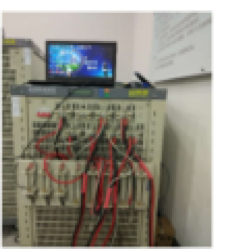

NEWARE Charge-discharge Device

Figure 1. Power test platform. 


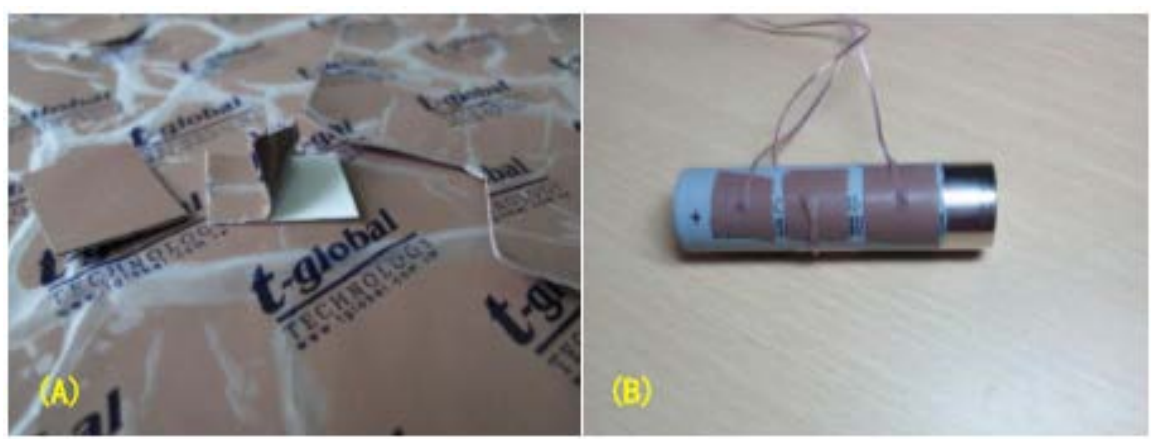

Figure 2. Distribution diagram of thermal conductive silica gel and thermocouple.

DEG) with self-viscous heat-conducting silica sheets will be $\mathrm{T}$ type thermocouple probe uniformly pasted on the cell surface, as shown in Figure 2(B), is used for temperature monitoring of battery discharge process changes.

The battery positive and negative terminal clamp and shown in Figure 1 NEWARE charge discharge testing instrument is connected to load as shown in Figure $3(\mathrm{~A})$ shows the state of the lithium ion battery card into the fixture as shown in Figure 3(B) is shown in Figure 1, placed in the high and low temperature thermostat. During the testing process, the battery is completely exposed to the test chamber of the constant temperature box, and the circulating constant temperature cold air is circulated in the storehouse, so that the battery can be cooled by convection heat transfer during the testing process. Test of low temperature discharge performance of a cell with convective heat transfer by experimental steps shown in Table 1 . The low temperature $\left(\mathrm{X}^{\circ} \mathrm{C}\right)$ in Table 1 represents $10^{\circ} \mathrm{C}, 0^{\circ} \mathrm{C},-5^{\circ} \mathrm{C},-10^{\circ} \mathrm{C},-15^{\circ} \mathrm{C},-20^{\circ} \mathrm{C},-25^{\circ} \mathrm{C}$ and $-30^{\circ} \mathrm{C}$, respectively.

\section{Low Temperature Discharge Experiment and Result Analysis of Battery}

Room temperature constant current and voltage when fully charged, the battery placed aside enough long time at 10 DEG and 0 DEG and -5 DEG and -10 DEG and -15 DEG and -20 DEG and -25 DEG C and -30 in low temperature environment, the whole cell and no temperature difference, have reached the required temperature, and then to $0.5 \mathrm{C}, 1 \mathrm{C}$, respectively. In order to test the discharge characteristics and discharge capacity of different rate at corresponding temperature, and to test the influence of low temperature discharge on battery capacity and battery impedance. Figures 4-6 are discharge curves of constant discharge at constant rates of $0.5 \mathrm{C}, 1 \mathrm{C}$ and $2 \mathrm{C}$ at different temperatures.

From the figure, no matter how much the discharge rate constant current discharge, the same magnification, the ambient temperature is low, the platform voltage of the battery is low, the average voltage is low, the discharge capacity is small, and the initial pressure drop more. As can be seen from the discharge curve, slope discharge platform under different temperatures are basically the same, only is the starting pressure different, the lower the temperature the more 

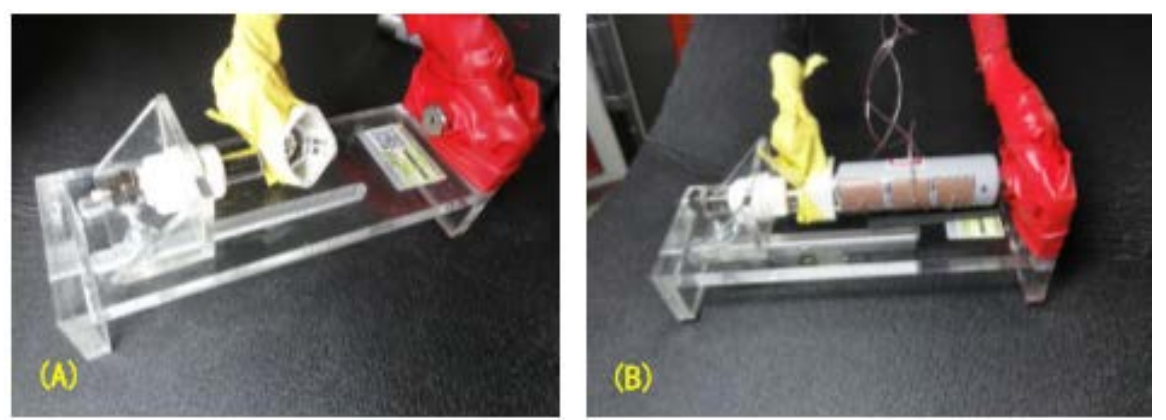

Figure 3. Battery clamp and installation method.

Table 1. Experimental steps of low temperature discharge performance test of battery.

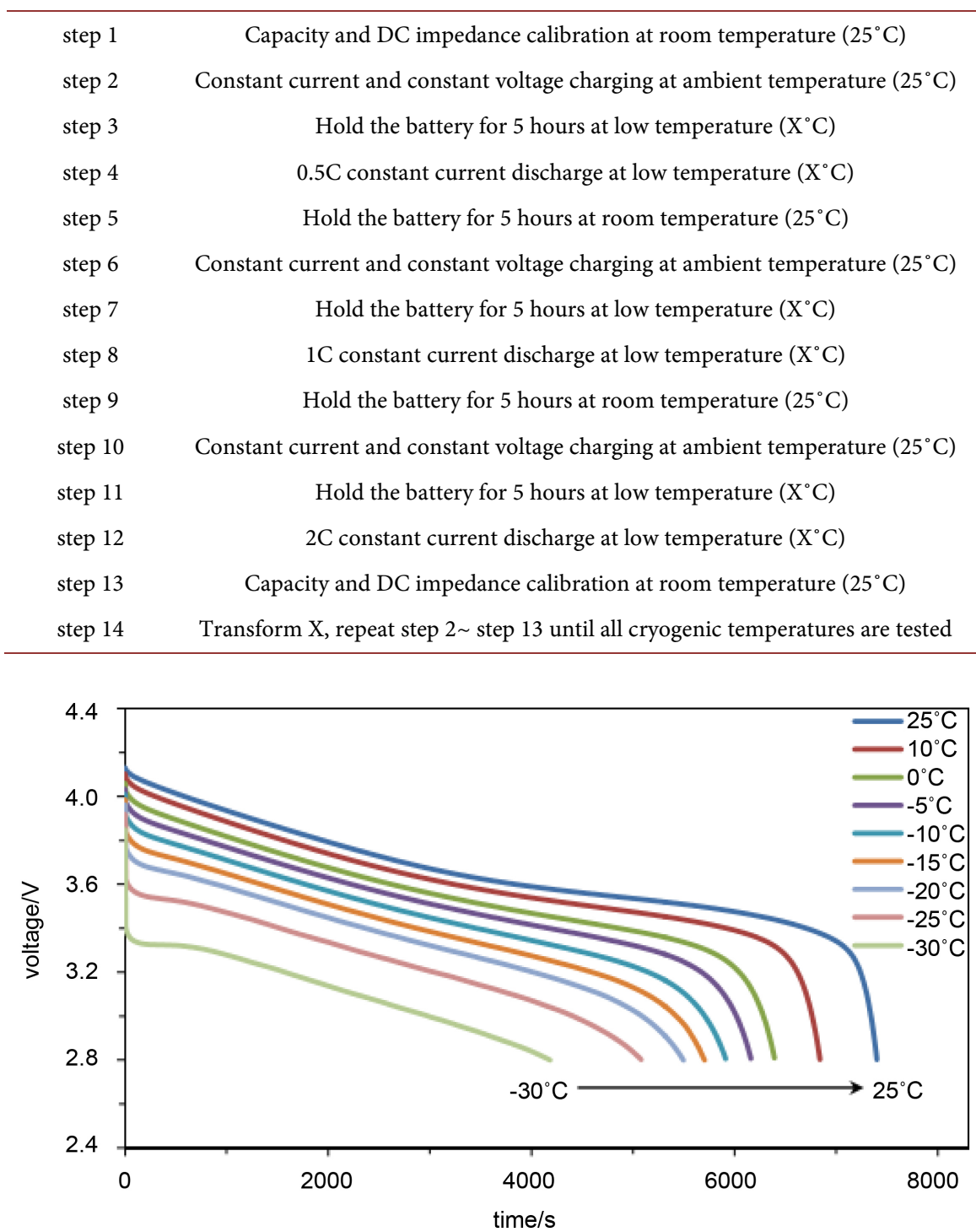

Figure 4. 0.5C rate discharge curve of Li ion battery at different temperatures.

downward shift, the fundamental reason is that with the decrease of temperature rising, the impedance of the battery, so the battery internal resistance partial 


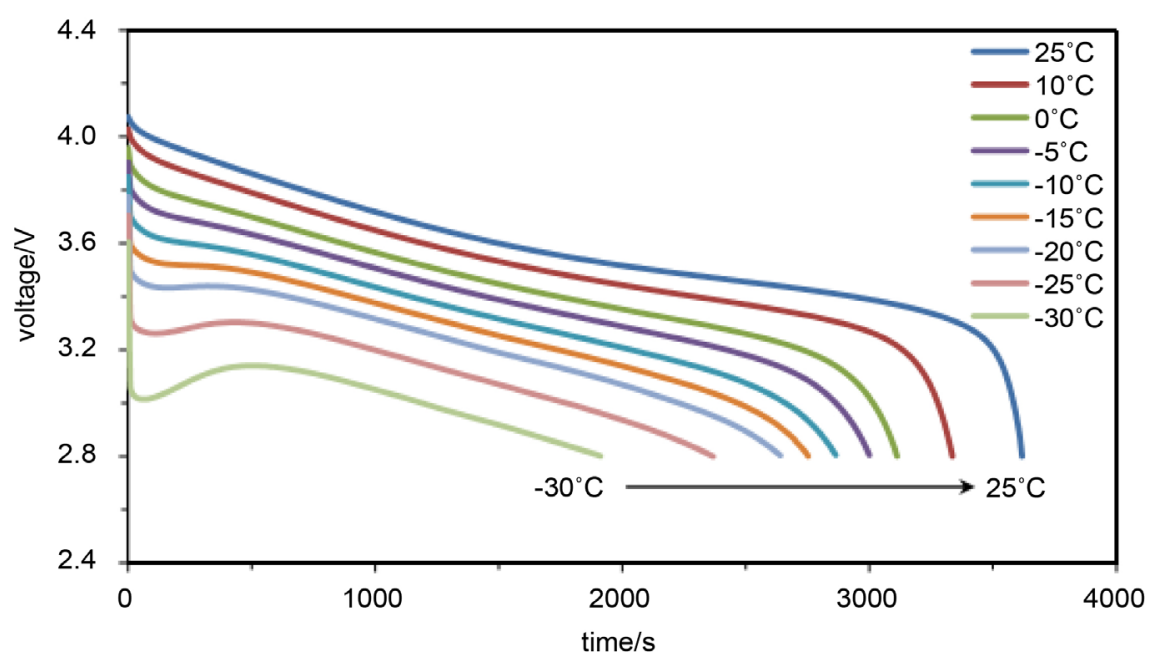

Figure 5. 1C rate discharge curve of Li ion battery at different temperatures.

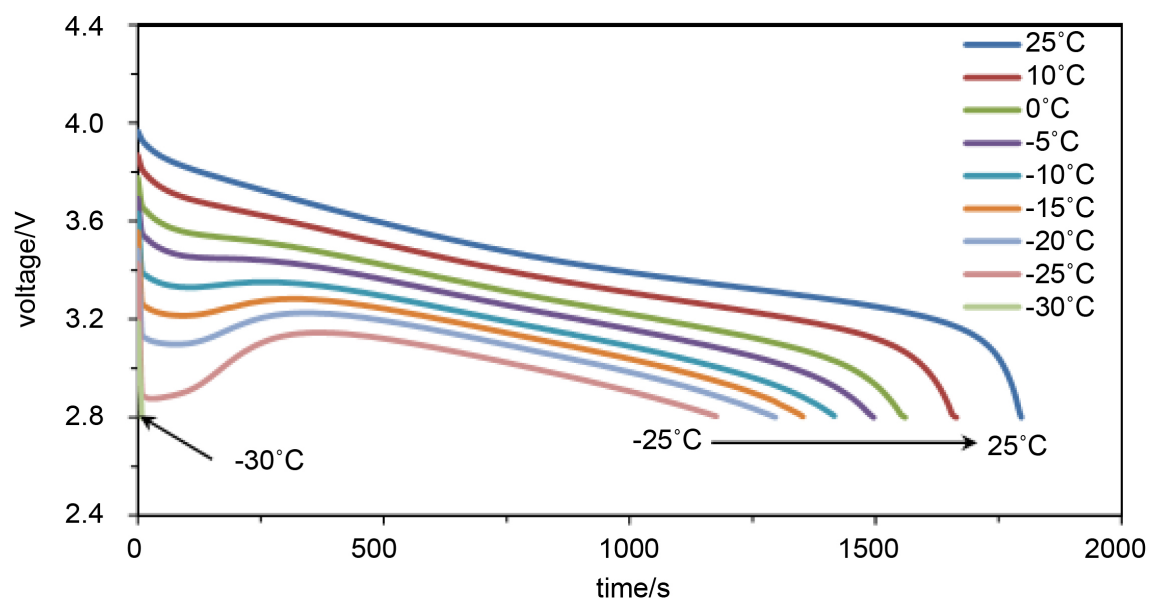

Figure 6. 2C rate discharge curve of Li ion battery at different temperatures.

pressure increasing, decreasing the output voltage of the battery. With the decrease of temperature, the battery capacity decreases, partly because the duration of the platform and voltage of the battery is shortened and that with the decrease of the temperature of the battery, the activity of lithium ion diffusion from the cathode gradually becomes less, on the other hand because of the internal resistance of the battery becomes large, internal pressure becomes larger, the battery reached earlier cut-off voltage. Comparison of different discharge curves of battery discharge rate increases, the initial discharge voltage is small, mainly because of the internal resistance of the battery under the same condition, the discharge current is, the higher the partial pressure resistance, so the output voltage of the battery is small. From the same rate discharge curve, it can be seen that with the decrease of temperature, the trend of voltage rise in the initial stage of battery discharge is more obvious, mainly because the omics heat power equation produced by the battery internal resistance is as follows:

$$
P=I^{2} R
$$


$P$ is omics heat power, it is battery discharge current, and $R$ is battery internal resistance. Energy conservation equation of heat generation and heat dissipation in battery.

$$
\rho C \partial T / \partial t=\lambda\left(T_{0}-T\right)+P
$$

Among them, the density of $P$ battery, $C$ capacity battery, $T$ battery temperature, $t$ time, lambda is the coefficient of thermal conductivity, $T_{0}$ temperature, $P$ battery heating power, the rate of change can appear on the left side of the battery, the first battery for the right side of the equation and the outside heat exchange power outside the temperature is higher than the temperature of the battery is the battery when the battery is heated, the temperature is higher than the outside temperature is battery cooling when the heating power is negative, the second item for battery. With the fall of the ambient temperature, the battery impedance $R$ increasing, omics heating power $P$ will produce more of the internal resistance of the battery, the temperature rise is faster, the temperature after the cell activity increased faster, resistance decreases more quickly, improve the battery output voltage is more obvious.

\section{Experimental Scheme of Low Temperature Charging}

In this section, a lithium ion battery with 18,650 or three materials is still used for low temperature charging. The experimental platform is the same as the experimental platform of the low temperature discharge performance of the battery in Figure 1. The experimental procedure is shown in Table 2.

\section{Experimental Results and Analysis of Low Temperature Charging}

Figure 7 is a constant current and constant voltage charging curve at different temperatures. The arrow in the picture refers to the end of charging. From the diagram, the lower the temperature, the higher the initial voltage of battery charging, the shorter the constant current charging time, and the longer the charging time in the constant voltage stage. Figure 8 is the battery charging

Table 2. Experimental steps for low temperature charging performance test of battery.

\begin{tabular}{|c|c|}
\hline step 1 & Capacity and DC impedance calibration at room temperature $\left(25^{\circ} \mathrm{C}\right)$ \\
\hline step 2 & $\begin{array}{l}\text { At constant temperature }(250.5 \mathrm{C}) \text {, the discharge was } 2.8 \mathrm{~V} \\
\text { constant at constant flow rate }\end{array}$ \\
\hline step 3 & Hold the battery for 5 hours at low temperature $\left(\mathrm{X}^{\circ} \mathrm{C}\right)$ \\
\hline step 4 & $\begin{array}{l}\text { At low temperature }\left(\mathrm{X}^{\circ} \mathrm{C}\right) \text {, the charge is first charged at } 0.5 \mathrm{C} \\
\text { constant current to } 4.2 \mathrm{~V} \text {, then the constant voltage is charged } \\
\text { until the current is less than or equal to } 0.1 \mathrm{C} \text {. }\end{array}$ \\
\hline step 5 & $0.5 \mathrm{C}$ constant current discharge at low temperature $\left(\mathrm{X}^{\circ} \mathrm{C}\right)$ \\
\hline step 6 & Capacity and DC impedance calibration at room temperature $\left(25^{\circ} \mathrm{C}\right)$ \\
\hline step 7 & Repeat 2 steps 2 - step 6 \\
\hline step 8 & Replace the battery, change X, repeat step 1 - step6 \\
\hline
\end{tabular}




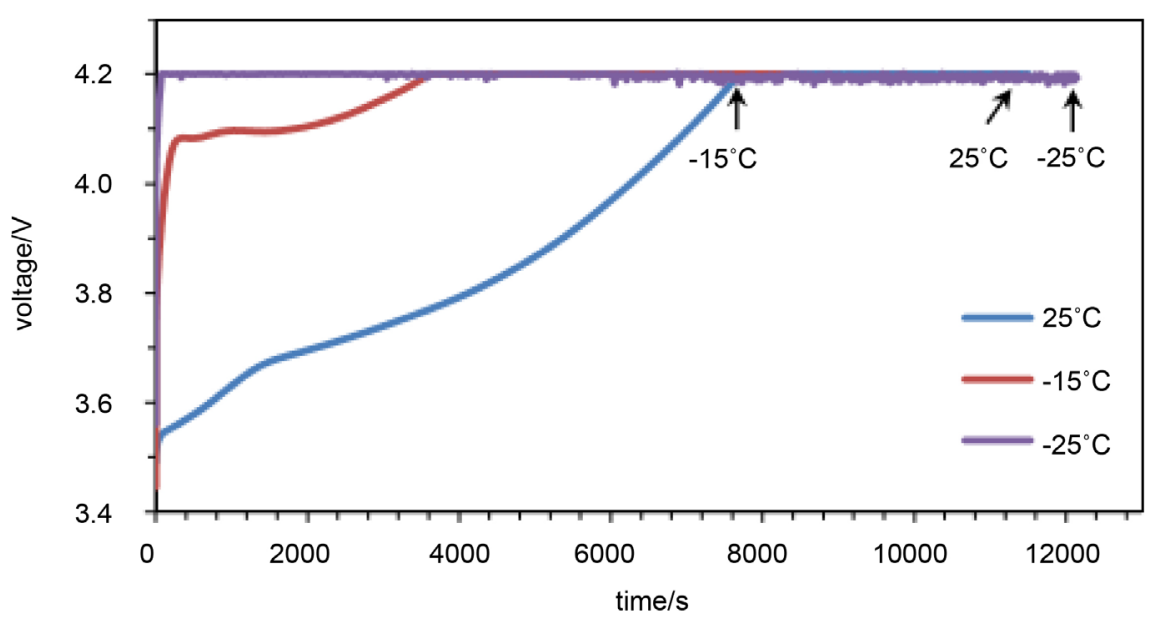

Figure 7. Constant current and constant voltage charging at different temperatures.

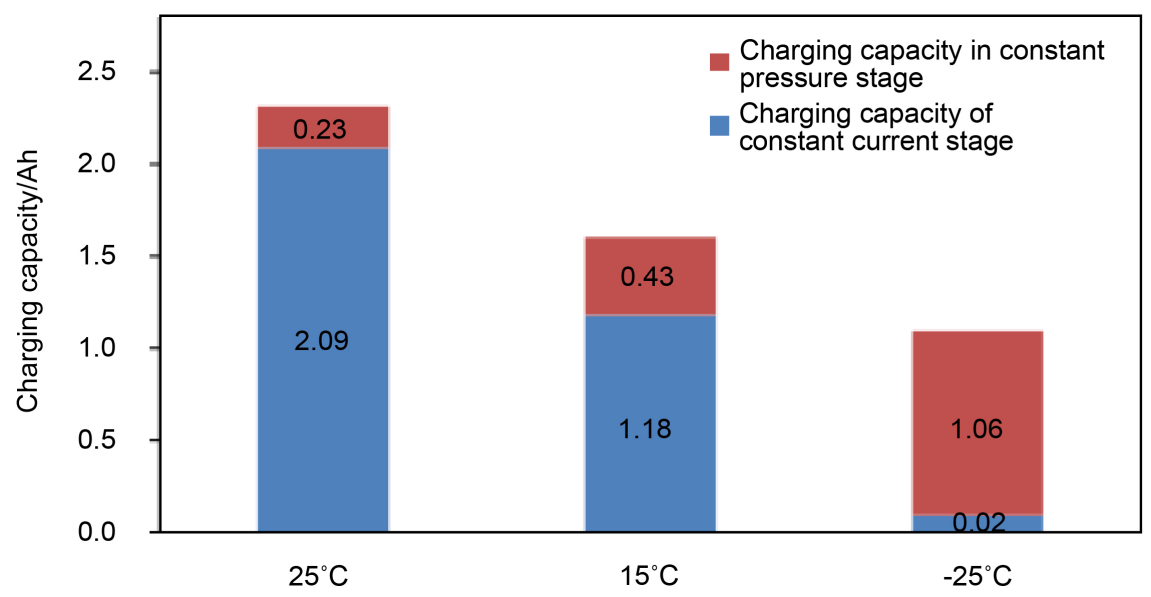

Figure 8. Charging capacity diagram of constant temperature and constant pressure with different temperature.

capacity in different temperature environment, including the constant current phase charging power and constant voltage phase charging power. From the combination of Figure 7 and Figure 8, with the decrease of temperature, the constant current charging power is greatly reduced, and the constant voltage charging power increases, but the time taken is longer. In the existing charging strategy for electric vehicle charger, the constant voltage charging stage has been canceled, retaining only the constant current charging stage, mainly because of small battery charging power in constant pressure stage, and time consuming, while the output power constant voltage charger to stage power is far less than its own consumption, so the constant voltage charging efficiency the stage is low, general measures are the ladder of the constant current charging, namely high constant current charging, constant current charging and small. At low temperature, the charge current of the battery constant voltage charging is smaller and the charging efficiency is lower, so it is more harmful to the battery charging in the low temperature environment. From Figure 8, with the decline of tempera- 
ture, the battery charging power decreased significantly, when -25 degrees, the charging power has dropped to $50 \%$ of the normal temperature charging power, seriously affecting the normal use of electric vehicles. If the constant voltage charging phase is canceled, -25 can only charge about $1 \%$ of the normal temperature charging power, which makes the electric vehicle unable to charge. So if you don't take heating measures, electric vehicles will be paralyzed at low temperatures.

\section{Cause Analysis of Low Temperature Performance Deterioration of Battery}

There are three different hypotheses about the deterioration of low temperature performance of lithium ion batteries:

1) the ionic conductivity of electrolyte is too low at low temperature;

2) the low conductivity of SEI film formed at the interface of solid and liquid at low temperature;

3) the solid phase diffusion coefficient of lithium ion in carbon anode material is too low at low temperature.

The above three assumptions are established in specific cases, because the performance of lithium ion batteries at low temperature is related to the positive and negative electrode materials used in batteries, and the solvents and solutes used in the battery electrolyte. The electrolyte solvent not only directly affects the liquids temperature range of the electrolyte, but also directly participates in the reaction of the SEI film. Increasing the conductivity of the electrolyte at low temperature can improve the low temperature performance of the battery, indicating that the low electrolyte conductivity at low temperature does lead to the deterioration of the performance of the lithium-ion battery. But lower under low temperature, the conductivity of electrolyte, while improving the conductivity of SEI film, the low temperature performance of the battery does not deteriorate further, but improved the conductivity of electrolyte, that is not the main reason leading to the deterioration of the low temperature performance of lithium ion battery, the electrical conductivity of SEI film under low temperature decrease effect on cell performance deterioration is much greater than the low temperature electrolyte ion conductivity decreased the deterioration of the performance of lithium ion battery.

\section{Conclusions}

The use of battery discharge heating will not cause permanent damage to the battery, but it needs to ensure sufficient battery power, and the use of large current discharge heating, the battery requirements harsh. The effect of low temperature discharge heating is higher than that under constant temperature condition, so the insulation effect of the battery should be improved as low as possible, and the heat dissipation coefficient between the battery and the outside should be reduced. 
Comparison of lithium ion battery discharge performance at low temperature and low temperature performance of the lithium ion battery charging, the charging performance of low temperature is fatal where the performance deterioration of its low temperature, low temperature discharge because although the deterioration does not impact on battery life, and battery charging power, not only low temperature charging, long charging time, but also have fatal damage to the battery, seriously affecting their life.

Lithium ion battery has poor performance at low temperature, although it is affected by ionic conductivity of electrolyte and ionic conductivity of SEI film, but it is mainly caused by lower solid diffusion coefficient of lithium ion in carbon negative electrode at low temperature.

Low temperature discharge performance was studied in this paper. The single cell, in order to better understand and apply it to the performance of electric vehicle batteries, after studying around the battery module, provides basis for the management of electric vehicle battery management.

\section{References}

[1] Zhang, S.S, Xu, K. and Jowl, T.R. (2006) Charge and discharge characteristics of a commercial $\mathrm{LiCoO}_{2}$-based $18650 \mathrm{Li}$-ion battery. Journal of Power Sources, 160, 1403-1409. https://doi.org/10.1016/j.jpowsour.2006.03.037

[2] Fan, J. (2003) On the Discharge Capability and Its Limiting Factors of Commercial 18650 Li-Ion Cell at Low Temperatures. Journal of Power Sources, 117, 170-178.

[3] Zhang, S., Xu, K., Allen, J.L., et al. (2002) Effect of Propylene Carbonate on the Low Temperature Performance of Li-Ion Cells. Journal of Power Sources, 110, 216-221. https://doi.org/10.1016/S0378-7753(02)00272-0

[4] Fan, J. (2004) Studies of 18650 Cylindrical Cells Made with Doped $\mathrm{LiNiO}_{2}$ Positive Electrodes for Military Applications. Journal of Power Sources, 138, 288-293. https://doi.org/10.1016/j.jpowsour.2004.06.010

[5] Nagasubramanian, G. (2001) Electrical Characteristics of 18650 Li-Ion Cells at Low Temperatures. Journal of Applied Electrochemistry, 31, 99-104. https://doi.org/10.1023/A:1004113825283

[6] Huang, C.K., Sakamoto, J.S., Wolfenstein, J., et al. (2000) The Limits of Low Temperature Performance of Li-Ion Cells. Journal of the Electrochemical Society, 147, 2893-2896. https://doi.org/10.1149/1.1393622

[7] Smart, M.C., Ratnakumar B.V., Whitcanack, L.D., et al. (2003) Improved Low-Temperature Performance of Lithium-Ion Cells with Quaternary Carbonate-Based Electrolytes. Journal of Power Sources, 119/120/121, 349-358. https://doi.org/10.1016/S0378-7753(03)00154-X

[8] Wang, C, Appleby, A.J. and Little, F.E. (2002) Low Temperature Characterization of Lithium-Ion Carbon Anodes via Micro-Perturbation Measurement. Journal of the Electrochemical Society, 149, A754-A760. https://doi.org/10.1149/1.1474427

[9] Fan, J. (2003) On the Discharge Capability and Its Limiting Factors of Commercial 18650 Li-Ion Cell at Low Temperatures. Journal of Power Sources, 117, 170-178. https://doi.org/10.1016/S0378-7753(03)00354-9

[10] Fan, J. and Tan, S. (2006) Studies on Charging Lithium-Ion Cells at Low Temperatures. Journal of the Electrochemical Society, 153, A1081-A1092. 
https://doi.org/10.1149/1.2190029

[11] Zhang, S., Xu, K. and Jowl, T.R. (2002) The Low Temperature Performance of Li-Ion Batteries. Journal of Power Sources, 115, 137-140. https://doi.org/10.1016/S0378-7753(02)00618-3

[12] Zhang, S., Xu, K. and Jowl, T.R. (2003) Electrochemical Impedance Study on the Low Temperature of Li-Ion Batteries. Electrochemical Alta, 49, 1057-1061. https://doi.org/10.1016/j.electacta.2003.10.016

[13] Zhang, S., Xu, K. and Jowl, T.R. (2006) Study of the Charging Process of a LiCoO2-Based Li-Ion Battery. Journal of Power Sources, 160, 1349-1354. https://doi.org/10.1016/j.jpowsour.2006.02.087

Submit or recommend next manuscript to OALib Journal and we will provide best service for you:

- Publication frequency: Monthly

- 9 subject areas of science, technology and medicine

- Fair and rigorous peer-review system

- Fast publication process

- Article promotion in various social networking sites (LinkedIn, Facebook, Twitter, etc.)

- Maximum dissemination of your research work

Submit Your Paper Online: Click Here to Submit

Or Contact service@oalib.com 